\title{
A CRIANÇA ENTRE SUJEITO E OBJETO*
}

Alain Vanier

\author{
Alain Vanier \\ Universidade \\ Paris VII Diderot, \\ Centro de Pesquisa \\ Psicanálise, \\ Medicina e \\ Sociedade, Paris, \\ França.
}

RESUMO: Trata-se de abordar, a partir da clínica da criança, dois aspectos da criança para o Outro primordial: o sujeito e o objeto. A criança ocupa para sua mãe um lugar de objeto, condensador de gozo, o que Freud já havia notado, fazendo da maternidade o lugar da perversão feminina. Porém, ao mesmo tempo, a mãe "supõe o sujeito" em seu filho, sob a condição que ela postule que este lhe faça signo.

Palavras-chave: criança, objeto, suposição do sujeito.

ABSTRACT: The child between the subject and object. Based on clinical work with children, we will discuss the two aspects a child takes on for the primordial Other: subject and object. For the mother, the child occupies the position of the object that condenses jouissance, as Freud noticed when he identified motherhood as the site of female perversion. However, at the same time, the mother also "supposes a subject" in the child, in so far as she assumes that she receives a sign from him.

Keywords: child; object; supposition of the subject.

\footnotetext{
* Texto retomado em uma conferência ministrada ao IRPA em Milão, em 23 de fevereiro de 2013. Uma primeira versão foi publicada em italiano em uma obra coletiva, sob a direção de Lucia Simona Bonifati e Chiara Tartaglione, Edições Mimesis, Milão, 2014.
} 
E u recebo a mãe de um bebê de cerca de seis meses. Ela vem sozinha, sem ele. As coisas têm se tornado muito difíceis em casa; ele dorme muito mal e acorda todas as noites. A mãe é obrigada a se levantar, pois ele só consegue dormir se ela fica a seu lado, e ela, para conseguir dormir, acaba, com muita frequência, por levá-lo para cama com ela e o pai da criança. Durante a entrevista, ela me conta que, desde o nascimento desta criança, a vida sexual com o marido não lhe interessa mais, chegando mesmo a evitá-la. Mas, de qualquer forma, os despertares noturnos de seu filho e a obrigação de retê-lo perto dela durante uma parte da noite, tornam essa questão sem validade. Nós marcamos um segundo encontro. Ela volta. Está tudo bem. Ela compreendeu, no momento daquela entrevista, o laço que eu havia sublinhado entre o favor que seu filho lhe prestava impedindo a retomada das relações sexuais com seu marido e suas insônias. Desde então, as relações sexuais com seu marido recomeçaram e milagre! — o menino dorme muito bem.

Trata-se de uma outra mãe cujo filho eu acompanho há vários anos. É um menino que tinha 4 anos quando o trouxeram para uma consulta comigo. Ele veio porque se coloca constantemente em perigo. Com 4 anos, já havia quebrado um braço caindo do alto de um armário, além de uma perna, por ter pulado da janela do segundo andar. Agora, os pais estão muito alarmados, pois eles o encontraram deitado no meio da rua ao lado de sua casa de campo. Eu não relatarei o tratamento dessa criança que eu acompanharei durante muito tempo, um menino psicótico. Ele me contará, aliás, que, quando se deitava no meio da rua, estava ao mesmo tempo no jardim olhando para a rua e se vendo deitado ali, para poder ver o efeito que causaria um carro passando por cima do seu corpo. O tratamento se desenrolará de uma maneira razoavelmente favorável; ele adotará um comportamento tendendo ao anti-social, como diz Winnicott, a tal ponto que a instituição onde ele será admitido aos oito anos, o expulsará, com a justificativa de que eles acolhem psicóticos, mas não delinquentes e que ele é totalmente inadaptável à instituição. Essa exclusão será sua sorte, pois ele entrará em uma escola normal com acompanhamento especializado. Mas o que eu gostaria de reter aqui é o fato de que, ao longo de seu tratamento, eu recebo um dia a mãe, que me contará que a relação que ela tem com esta criança é, desde o seu nascimento, bem particular. Mais especificamente, ela não consegue ter relações sexuais com seu marido quando o menino está em casa.

Eu escolhi, propositadamente, estes dois exemplos que giram em torno da atividade genital da mãe, para trazer à tona dois lugares que podem ser ocupados pela criança no que se refere a essa questão. Se Freud pôde abordar o pequeno Hans referindo-se principalmente à questão do pai e da castração, e se sua lição continua ainda imprescindível para os que trabalham com a psicanálise da 
criança, Lacan detalhou essa abordagem em Nota sobre a criança ${ }^{1}$. De fato, essa Nota sobre a criança, primeiramente apresentada como Duas notas sobre a criança, foi encontrada entre os papéis de Jenny Aubry. Ela data do fim de 1969 (outubro). Lacan incorpora os avanços da obra de Maud Mannoni, publicação inaugural de sua nova coleção pelas edições Seuil em 1964, A criança retardada e a mãe. Na história da psicanálise da criança na França, com Françoise Dolto, a ênfase terá sido posta sobre a questão do pai e, consequentemente, do Édipo. Lacan se orienta, no início, na mesma perspectiva que Dolto: ele aborda, assim, em seu seminário sobre $A$ relação de objeto, o pequeno Hans, em termos de função paterna e de castração ${ }^{2}$. A obra de Maud Mannoni sobre a criança retardada, assim como suas obras subsequentes, colocam em primeiro plano a noção de objeto ${ }^{3}$. Lacan comenta esta aparição no Seminário XI, colocando em série a debilidade, a psicose e o fenômeno psicossomático como testemunho de uma holófrase da primeira dupla de significantes, a saber, da impossibilidade de inscrição do sujeito no discurso e da não produção do objeto. A Nota, anteriormente chamada, então, de Duas notas sobre a criança, já que o documento estava escrito em duas folhas diferentes, possui duas partes bem distintas. A primeira parte dá ao sintoma da criança o estatuto de representante da verdade do casal da família. Lacan sublinha, aliás, que é, ao mesmo tempo, o caso mais complexo, mas também “o mais aberto às nossas intervenções”. Nessa primeira parte, as funções da mãe e do pai são detalhadas, consistindo em fazer com que o sujeito seja inscrito na relação com um desejo que não seja "anônimo”. Isso significa, em outras palavras, que essa primeira versão do sintoma tem como referência a dimensão fálica, visto que se trata do casal, e é o que encontramos na minha primeira vinheta clínica. $\mathrm{Na}$ segunda parte dessa Nota sobre a criança — ou na segunda nota, como queiram Lacan incorpora a visão de Maud Mannoni quando ele indica que "a articulação reduz-se bastante quando o sintoma que passa a dominar concerne à subjetividade da mãe. Aqui, é diretamente como correlato de uma fantasia que a criança está interessada”. A criança, então, “torna-se o objeto da mãe”; ela "realiza a presença do que Jaques Lacan designa como o objeto a no fantasma”, fantasma que a satura. Temos, então, por um lado, uma criança cujo um dos pais vai mal ou está com uma dificuldade conjugal e que, devido ao seu sintoma, conduz um desses pais até nós, cuja análise passamos a conduzir. O sintoma da criança desapareceu milagrosamente no momento em que o sofrimento de um desses pais encontrou uma boa escuta. E, por outro lado, a criança saturando a fantasia

\footnotetext{
${ }^{1}$ J. Lacan. Note sur l'enfant (1969). In: Autres écrits, Paris, Seuil, 2001.

2 S. Faladé. Ce que Françoise Dolto m’a enseigné. In: l’Enfant et la psychanalyse, Paris, Éd. Esquisses psychanalytiques C.F.R.P., 1993.

3 J. Lacan. (1964). Les quatre concepts fondamentaux de la psychanalyse, Le Séminaire XI, Seuil, 1973.
} 
materna, tomada em uma relação dual, de onde "resulta que, à medida do que apresenta de real, ela é oferecida a um suborno maior na fantasia”.

Essa dupla faceta será retomada por Lacan bem mais tardiamente, situando ainda de outra maneira a questão da criança, mas, na verdade, unificando, de uma certa forma, essa duas facetas, sem com isso reduzi-las. Efetivamente, Lacan acabará por situar a criança, em todos os casos, como objeto a da mãe, o que é uma forma de contrapeso ao pensamento dominante da época, que é o de considerar a criança como sujeito ${ }^{4}$. O que não quer dizer que ela não o seja, mas que o analista não deve desconsiderar o lugar de objeto que terá sido, fundamentalmente, o dela. Criança-falo para Freud; criança-objeto a para Lacan. Na verdade, isso não é contraditório.

Dois anos antes, em 1967, Lacan insistia na necessidade de que a mãe não tomasse a criança como objeto transicional. A perversão feminina tem seu lugar normal na maternidade. Freud escreveu: “O amor da mãe pelo seu bebê que ela amamenta e cuida é alguma coisa que tem uma profundidade muito maior que sua afeição posterior pelo filho adolescente. Esse amor possui a natureza de uma relação amorosa tão satisfatória que preenche não somente todos os desejos psíquicos, mas também todas as necessidades corporais, e se ele representa uma das formas de felicidade acessível ao ser humano, isso não provém de forma alguma na possibilidade de satisfazer sem reprovações igualmente as moções de desejos recalcados há muito tempo e que é conveniente designá-los como perversos" 5 . Aliás, Lacan comentava em 1959: “Se há menos perversões nas mulheres do que nos homens, é que elas geralmente satisfazem suas relações perversas na relação que elas têm com seus filhos". Ele, então, simplesmente se lembrou de Freud.

Desde 1969 existe, então, essa oposição, ligada à maneira como Lacan pode integrar os desenvolvimentos de Mannoni. Creio que será mais de acordo com a experiência lê-la como algo que desenvolve as variantes do sintoma da criança, sem que o primeiro exclua o segundo e assim reciprocamente. A respeito da primeira vinheta que eu apresentei, o fato de dormir com a criança permitiu à mãe escapar das demandas sexuais do marido que ela não suportava mais. O fato de ter podido dizer isso a ele e de ter conseguido retomar uma vida sexual não significa que ela retomou essa vida sexual com muito entusiasmo. Por um lado, a perversão materna, se é normal, explica mal o sintoma somático que Lacan colocará em relevo, colocando-o em série com a psicose e a debilidade. De fato, não há porque considerarmos que a culpabilidade inconsciente da mãe, dentro da qual a criança é tomada, seja a esse ponto prejudicial, pois eu não conheço nenhuma mãe para quem a criança não esteja mais ou menos em posição de

\footnotetext{
4 J. Lacan. R.S.I. Le Séminaire. Livre XXII (1974-1975), inédito.

5 S. Freud. Un souvenir d'enfance de Léonard de Vinci (1910r), Paris, Gallimard, 1987.
} 
testemunhar sua culpabilidade edipiana inconsciente. Na verdade, o texto de 1969 atém-se à dificuldade de Lacan, naqueles anos, em articular objeto a e falo, que o ocupará por toda a década. Ele avança uma solução em dois tempos. No início, propõe quatro discursos, destacando que não precisou do falo para escrevê-los e ele se surpreenderá, na ocasião de um congresso da Escola Freudiana em Paris, que ninguém o chamou a atenção para isso, que ninguém o tenha percebido. Efetivamente, sem referência ao falo, não há laço social. E, efetivamente, não há necessidade do falo, diria ele, porque ele está subentendido, ele é a condição mesma dessa escrita. Com as fórmulas da sexuação, o falo torna-se função fálica, separadora, função da falta. O objeto a se distingue, dependendo de ser ou não falicizado, quer dizer, separado, e é toda a distância do desejo ao gozo, ou simplesmente, a possibilidade do desejo. Contudo, quando ele não é separado, ele não é verdadeiramente objeto a. Eis porque Lacan proporá, em 1975, uma solução: “Um pai só tem direito ao respeito e ao amor se o dito respeito é — vocês não irão acreditar em seus ouvidos — pai-versamente (père-versement) orientado, isto é, faz de uma mulher objeto a que causa seu desejo. Mas o que essa mulher a-colhe disso, se posso exprimir-me assim, nada tem a ver com a questão. Aquilo de que ela se ocupa é de outros objetos a, que são os filhos, justos aos quais o pai, no entanto, intervém - excepcionalmente, na melhor das hipóteses — para manter na repressão, no justo meio-Deus, se me permitem, a versão que lhe é própria de sua perversão, única garantia de sua função de pai, que é função do sintoma tal como eu a escrevi”'6. É, então, porque a mãe é um a para o pai, quer dizer, é porque ela causa seu desejo, que ela pode acolher a criança em posição de objeto a. A pai-versão do pai permite — ou ao menos sustenta — essa perversão feminina normal que é a maternidade. Assim, a criança, objeto a da mãe, causa do desejo, mais-de-gozar, com o equívoco desse "mais" que inclui um sentido privativo, um limite, é o valor de alguma coisa que poderia se recuperar e que circula no laço social.

Para ilustrar, eu gostaria de evocar minha experiência com mães psicóticas e seus bebês, quando eu dirigi o serviço de psiquiatria em um hospital que acolhia mães com grandes dificuldades, dentre elas mães psicóticas ${ }^{7}$. Entretanto, elas apresentam, frequentemente, o que há de mais inteligível para apreender o que quer dizer "objeto a da mãe” quando esta dimensão não é elidida. E, curiosamente, as mães psicóticas são mais tranquilas durante a gravidez, que frequentemente não é reconhecida por elas, e será no pós-parto mais tardio que a situação não vai bem. Uma de nossas pacientes, por exemplo, parou de trocar de roupa e de tomar banho, e passou a se vestir somente com uma roupa

\footnotetext{
${ }^{6}$ J. Lacan. R.S.I. Le Séminaire. Livre XXII, op. cit.

${ }^{7}$ Ver A. Vanier, "D'une dyade à plusiers. Quelques remarques à propos d'un travail avec des mères psychotiques et leur nourrisson”, Psychologie clinique, nº 12, 2001/2. Paris, 2002.
} 
durante dias, um pijama uniformemente amarelo, que ela se recusava a tirar, durante várias semanas. Dois dias antes do parto, ela aparecerá no serviço em um domingo à tarde, completamente nua, gritando: "que me tirem o que eu tenho na barriga e que isso acabe". A crise será muito rapidamente resolvida pela recolocação do famoso pijama amarelo. Ela só conseguirá trocar de roupa depois do parto. A roupa teria tido para ela a função de manter a integridade corporal, de envolver o corpo através de sua função de borda de superfície, em um momento em que esta unidade estava particularmente ameaçada. A borda do pijama amarelo tornou-se necessária assim que a criança começou a se mexer na barriga e quando ela pôde sentir os movimentos da criança. O pijama era o que permitia manter a totalidade do corpo sem a ruptura produzida por este objeto que qualquer mulher pode suportar, na medida em que ele signifique para ela que o que ela carrega em sua barriga, é aquilo ao qual ela é chamada a se separar.

Uma outra paciente acabava de dar à luz a uma menininha a quem havia dado seu próprio nome. A criança, não sendo reconhecida pelo pai, portava, então, o mesmo nome da mãe. A relação especular é marcada, não somente pela similitude dos nomes, mas também por um certo número de manifestações ligadas ao olhar. Ela não pode olhar para sua filha, não mais que a equipe; ela usa o tempo todo óculos de sol, inclusive na penumbra do quarto. Ela dá mamadeira ao bebê à distância: a criança é colocada sobre a cama, a mamadeira escorada nas orelhas; ela mesma permanece em pé, com o olhar fixado no chão. As persianas do quarto ficam fechadas, as cortinas também. Ela começa aos poucos a desenvolver um delírio de vigilância. O olhar ganha uma amplitude, olhar persecutório, gozador, não separado; este olhar que é este bebê que carrega exatamente seu nome. Aliás, ela poderá dizer que a troca de olhares com o bebê significaria a morte de um dos dois. Esta vinheta clínica permite compreender de outra maneira algumas expressões populares que caíram em desuso, mas que eram usadas para se referir a uma criança. Algumas mães diziam "meus olhos", mas também "meu bombom"8, ou seja, nada menos do que a equação criança $=$ falo $=$ excremento, evocada por Freud, e que Lacan havia longamente comentado em um primeiro seminário.

Mas voltemos a esta mulher. Em sua chegada ao serviço, ela era muito discordante, mantinha estranhas conversações, sua fala se interrompia sem razão aparente e evitava o olhar. Não podia nos olhar, assim como não podia olhar para sua filha quando ela nasceu. A puericulturista que se ocupava dela descreveu o primeiro dia: “a criança mama mal e dorme muito”. Eu proponho a esta mãe

\footnotetext{
${ }^{8}$ Nota do tradutor: Em francês, as expressões "mes yeux" e "ma crotte" são expressões afetuosas. Curiosamente, a palavra "crotte" significa excremento, mas também coisa sem valor ou ainda bombom de chocolate. Nos dois casos, o autor pretende sublinhar, ao utilizar estas expressões, que essas mães designam a criança por termos que são objetos parciais.
} 
olhar para o seu bebê mamando e não olhar para o seu bebê. Ela aceita, mas tem necessidade da minha presença. Muito rapidamente, eu lhe proponho a deixar a criança no berçário. Nós dizemos a ela que a criança poderá ficar lá em alguns momentos, que poderá ver a filha quando quiser, e que poderá cuidar dela na presença da puericulturista, de forma que a puericulturista pudesse falar com ela e com a criança, ou seja, falar com ela na presença da criança e se dirigir à criança em sua presença. Ela vai, cada vez mais, deixar a filha com as puericulturistas, e veremos regredir nessa menininha os pequenos sinais inquietantes que nos tinham alertado: sua sonolência, sua dificuldade em fixar o olhar etc. A mãe vai, pouco a pouco, jogar com essa distância que vai desenvolver com a criança na medida de sua permanência no serviço. Percebemos, aliás, que se a regulação da distância fosse suficiente para organizar essa situação, estaríamos diante de uma solução fóbica a um problema que se coloca em outro nível.

Um mês mais tarde, a puericulturista observa: "Eu coloco a criança em seus braços, em frente a ela; ela a olha, fala com ela, chama-a de 'minha pequena'. Esta criança que dormia muito, que mamava mal, agora acompanha com o olhar e é atenta quando falamos com ela". Neste dia, a paciente se espanta ao ver seu bebê "em pé", isto é, encontrando apoio em seus braços. Ela diz: "ela mudou, minha pequena”. Apoiada nesta revalorização narcísica, é ela quem vai mudar e deixar seu bebê cada vez mais tempo no berçário. Ela delega cada vez mais à equipe os cuidados com a criança, dando-lhes ordens como se fossem empregados de sua casa. Felizmente, a equipe suporta este semblante, instaurando-se neste jogo, que acontecia com algumas ramificações delirantes. No dia da visita da família adotiva, já que esta mulher não tem domicílio e que será preciso que a criança seja colocada em algum lugar, ela dirá: "a puericulturista vai falar com vocês sobre a minha filha; é ela quem se ocupa do bebê quando eu não estou aqui". Para esta mãe, a criança tinha a incumbência de regular a questão de seu próprio lugar. Esta menininha veio em um momento em que ela se encontrava completamente perdida, sem nenhum apoio familiar ou institucional. Com efeito, a colocação $0^{9}$ de sua filha em uma família adotiva - a palavra "lugar" é particularmente importante e retorna regularmente em seus propósitos - lhe havia permitido encontrar o seu próprio lugar: havia pessoas para tomar conta dela e orientá-la, assim como uma ajuda financeira substancial que, na França, é regularmente paga neste tipo de situação. Deste novo nascimento, ela espera o mesmo efeito, isto é, encontrando um lugar para esta menina que é seu homônimo, ela encontra o seu próprio lugar. Desta evolução, testemunha a emergência ou a explicitação de um delírio de filiação: ela não é africana, mas francesa.

\footnotetext{
${ }^{9}$ Nota do tradutor: no original, temos o uso da palavra "placement", que significa "colocação" e remete à ideia de lugar, de colocar alguém em algum lugar, de instalar, de localizar ou situar.
} 
Em todo caso, quer ser reconhecida assim, e será desta menina nascida em solo francês que ela obterá esta nacionalidade reivindicada. Estranha construção em que o delírio com a inversão da filiação — ela obterá a nacionalidade de sua filha — se mistura à verossimilhança das disposições legais.

Quem cuida de pais psicóticos e de seus filhos sempre sublinhou a importância da inclusão no delírio. Para uma outra paciente, a psicose se situa não em uma vertente esquizofrênica, mas, sobretudo, em uma vertente paranóica. É uma mulher de mais de 40 anos, que está na primeira, e inesperada, gravidez, mas que parece estar particularmente feliz com ela. Ela apresenta um vasto delírio de perseguição, muito sistematizado e estável, ligado à administração do local onde ela trabalhou. Este delírio acontece principalmente pela via da intuição e da interpretação, e ela não apresenta alucinações. A permanência no serviço, bem antes do parto, acontece em um clima quase que de euforia. O local é protegido, inatingível pelos perseguidores. Há um pai para esta criança, muito presente, mas bastante singular, que reconhecerá a criança antes do nascimento, mas desaparecerá — provisoriamente — ao final da internação.

Mas, depois do parto, ela não se sente mais segura no serviço. A partir do dia seguinte, ela avistou no parque uma caminhonete branca. Ela pertence, sem dúvidas, a seus perseguidores que ela designa como tais. O local é, então, permeável; pode-se invadi-lo. Ela terá um período bastante agitado. Alerta a polícia e pede para trazer os policiais ao serviço ou até a casa de seus pais, pois sentia que eles estavam igualmente ameaçados, o que, sem dúvida, é uma modalidade de interrogação sobre a filiação. Ela se tranca em seu quarto e, se eu sou o único a poder entrar lá, ela mantém, entretanto, um sistema de relações corretas com a equipe. Ela aceita e mesmo demanda que sua filha esteja sempre que possível no berçário, enquanto ela mesma se mantém fechada em seu quarto. A criança se encontra, para ela, fora do circuito de perseguição. Entretanto, esta exclusão não é total; o perigo para a criança, segundo ela, só será questão depois da puberdade. Esta menininha permanecerá no berçário e sua mãe virá cada vez mais regularmente para lhe dar os cuidados necessários, saindo-se particularmente bem. Não se pode dizer que esta relação seja marcada de forma calorosa, mas os cuidados são adequados e de qualidade suficiente para que a criança não apresente nenhum distúrbio notável. Aliás, ela explica sua vigilância em relação a sua filha dizendo que só pode pensar nela imaginando-a adolescente. Ela nos fala, então, de suas múltiplas inquietações concernentes a esta menina quando ela se tornar adolescente: sobre seus amigos, a saída da escola, a droga, a delinquência e, claro, o interesse que ela vai suscitar nos perseguidores. Da criança atual, de quem ela fala muito pouco, diz: "É como um poodle”. Neste tipo de delírio, a criança é menos o duplo que o ideal. Isto supõe, entretanto, que esta instância esteja no lugar e funcionando. O nome que ela escolhe para 
esta criança o atesta. Seu sobrenome é o mesmo que o de uma célebre atriz e ela decidiu dar a sua filha o mesmo nome dessa atriz. O único percalço neste caso é que o pai reconheceu a criança antes dela e a homonimia fracassou. Ela considerará apagar o patrimônio paterno para que o seu o substitua.

Mas o caso prínceps é o artigo de Winnicott de $1961^{10}$. Trata-se do caso de Esther. A mãe de Esther é psicótica. Esta mãe "pode ter dado a seu bebê um começo excepcionalmente bom”. Mas em um dado momento — é, aliás, sempre depois de um certo tempo, quando o bebê demanda outra coisa, quando o circuito da demanda se coloca no lugar, é que advém um momento muito difícil para essas mães - a mãe de Esther joga-a em um canal, depois de ter passado, se fazendo notar, perto de um velho agente da polícia que cavava ali um buraco: ele salvará a criança.

O bebê que se joga, este objeto que cai, puro rebotalho, a presença de um representante da lei, e mesmo o buraco que ele cava: eis aqui todas as coordenadas das proposições de Lacan. Além do mais, Winnicott comenta: “Ela podia jogar o bebê, mas ela não podia se separar (separate) ela mesma do bebê”. Trata-se da separação que somente a colocação em jogo da função fálica permite - "ela queria se desfazer de seu bebê com quem estava fusionada, com quem fazia um..." - esta separação que somente pode ser, neste caso, real, é mortal. Então, a criança se iguala ao excremento etc.; criança como objeto parcial, ou antes, encarnação, substância episódica do objeto a. Mas ela é este objeto? Não, pois o objeto a não é nenhuma destas figuras, nenhuma dessas quatro substâncias episódicas, nem o fetiche, nem nenhum gadget. O objeto a não é presentificável; ele se demonstra retroativamente como o que "antes fazia toda a estrutura do sujeito". Ele se manifesta como um dos "quatro apagamentos em que se pode inscrever o sujeito". Com efeito, é como causa do desejo, mas, antes de tudo, como objeto de gozo que o sujeito terá existido para o Outro. É este ponto diante do qual, aliás, no tratamento analítico de adultos, nós resistimos.

Este gozo, que teria sido perdido, continua vivo, vibrante, em certas análises de crianças. Se ela é um objeto para a mãe, e objeto condensador de gozo, pertence à mãe também supor algo do sujeito nesta criança. Eu pude sustentar que, como sujeito, a criança existe, primeiramente, na mãe, no lugar do Outro, pois é a mãe que supõe um sujeito em seu filho, que o carrega, e supõe este sujeito ao mesmo tempo em que ela o representa como estando separado antes mesmo que ele possa falar ${ }^{11}$. Os observadores do desenvolvimento se interessaram bastante

\footnotetext{
${ }^{10}$ Winnicott, D. W. (1959), “The effect of psychotic parents on the emotional development of the child”. In: The family and individual development. Londres, Tavistock Publications, 1965, rééd. Routledge, 1999.

${ }^{11}$ Esta tese foi progressivamente desenvolvida em diversas comunicações e publicações: A. Vanier, "Évaluation, soutien, orientation pour les enfants de mères marginales à la période
} 
pelo período dito turn talking, proto-diálogos entre mães e bebês. É um momento fugaz, geralmente no curso do segundo mês, que dura duas ou três semanas. A mãe fala, a criança faz lalações. Nestas observações, eu pude ler que, logo que a criança emite um fonema, a mãe o confirma ou o atesta, mas quando ela emite dois, a mãe, então, fala com a criança, a mãe diz "eu” para ela; ela mesma pergunta e responde. E este sujeito, a criança o terá sido no futuro anterior, para aquém ou para além de seu próprio ser, de seu ser de objeto. É por isso que Lacan poderá sustentar que só há verdadeiramente sujeito quando o sujeito fala. É sem dúvida por isso, nesta articulação tensa entre sujeito e objeto, que Lacan pôde dizer que a psicanálise com crianças é o que há de mais difícil. Com efeito, se a não-relação sexual, isto é, o real, é o fundamento da psicanálise, há, apesar disso, relação sexual possível entre "as gerações vizinhas, a saber, os pais, de um lado e as crianças, de outro", do fato precisamente do papel do objeto: "É nisso que aposta a interdição do incesto”, poderá dizer Lacan muito tardiamente. Visto que a criança é o desejo — é assim que ela se identifica —, ela é também gozo. "Fazemos nossos pequenos que são pequenos objetos a. É assim que eles são desejados e é isso que eles encontram”. Será também deste fato que Lacan poderá dizer que somos todos objetos a, isto é, "tantas falsas camadas daquilo que foi, para aqueles que nos geraram, causa do desejo”.

Uma mãe, antes mesmo de supor um saber, supõe um sujeito na criança. O significante que suporta este sujeito é, enquanto tal, desconhecido. Pois a criança é, para ela, o lugar da falta, ao que ela responde pelos cuidados com a alimentação. Essa falta faz signo. Do saber que ela coloca na criança, sem o seu conhecimento, isto é, o significante que sustenta sua presença no mundo, ela recebe o signo. "O signo não é, portanto, signo de alguma coisa, mas de um efeito que é aquilo que se supõe enquanto tal de um funcionamento do significante". Este efeito do significante é o sujeito. Citemos Lacan: "O sujeito não é outra coisa senão o que desliza na cadeia de significantes - quer ele tenha ou não consciência de que significante ele é o efeito - -". No amor da mãe, como em todo tipo de amor, o que é visado é o sujeito enquanto tal. E o sujeito enquanto tal não tem muita coisa para fazer com o gozo, "mas, por outro lado, seu signo é susceptível de provocar o desejo. Aí está a mola do amor". Ele pode estar subordinado ao significante, mas ele não permanece assim, pois é pelo viés deste signo que a mãe supõe um sujeito na criança e que, por sua vez, ela faz signo

périnatale”, em colaboração com a Dra. Nicole Pelletier, IV Congresso mundial da WAIPAD, Lugano, 20-24 setembro de 1989; A. Vanier, “Autisme et théorie”, in Hommage à Frances Tustin, éd. Audit, 1993; A. Vanier, Contribution à la métapsychologie du temps des processus psychiques. Questions posées par l'observation et la clinique infanto-juvénile, tese de doutorado de psicopatologia fundamental e psicanálise, 1995, inédito; A. Vanier, "D’une dyade à plusieurs. Quelques remarques à propos d'un travail avec les mères psychotiques et leur nourrisson", in Psychologie clinique, $\mathrm{n}^{\circ}$ 12, 2001/2002; etc. 
a este sujeito que vai carregar com ela, mesmo depois do nascimento. É aí que, dessa mãe, surge um significante no Outro e esse significante que virá alienar o sujeito, fundando-o, mas deixando como enigma o que a criança terá extraído do olhar de sua mãe, a saber, que ela representa alguma coisa para a mãe sem saber o quê, um enigma para ambas. É, então, que a criança poderá surgir como sujeito. “Dizer que há sujeito, não é outra coisa senão dizer que há hipótese. A única prova que nós temos que o sujeito se confunde com essa hipótese, e de que é o indivíduo falante que o suporta, é a de que o significante se torna signo”. Lacan acrescenta, "entendam esse signo como lhes agradar, inclusive the thing em inglês, das Ding, a Coisa”. O significante é o signo de um sujeito; é por isso que a mãe fala para responder ao que retorna para ela de fora na criança como signo. Signo esse que é, por certo, de um suporte significante, mas também da parte do gozo desta Coisa que a linguagem vai esvaziar, e que só subsiste na lalíngua.

Recebido em: 10 de maio de 2015. Aprovado em: 3 de novembro de 2015.

\section{REFERÊNCIAS}

FALADÉ S. Ce que Françoise Dolto m’a enseigné. In: L’enfant et la psychanalyse (Coll.). Paris: Esquisse psychanalytique, CFRP, 1993.

FREUD S. Un souvenir d'enfance de Leonard de Vinci. Trad. J. Altounian, A. et al. Paris: Gallimard, 1991.

LACAN J. Autres écrits. Paris: Seuil, 2001.

Le Séminaire, livre IV. La relation d’objet. Texte établi par J.-A. Miller. Paris: Seuil, 1998.

Le Séminaire, livre XI. Les quatre concepts fondamentaux de la psychanalyse.

Texte établi par J.-A. Miller. Paris: Seuil, 1973. Le Séminaire. Livre XVII. L'envers de la psychanalyse. Texte établi par J.-A. Miller. Paris: Seuil, 1991. Le Séminaire. Livre XXII, RSI. Inédit.

MANNONI M. L'enfant arriéré et sa mère. Paris: Seuil, 1964.

VANIER A. D'une dyade à plusieurs. Quelques remarques à propos d'un travail avec des mères psychotiques et leur nourrisson. Psychologie Clinique, $n^{\circ} 12,2001 / 2$. Paris, 2002.

Une métapsychologie des premiers temps. In: L'enfant et la psychanalyse (Coll.). Paris: Esquisse psychanalytique, CFRP, 1993. 
Alain Vanier

alainvanier@noos.fr

Tradutores

Fabiana Campos Baptista

Doutora em Psicopatologia e Psicanálise (Universidade Paris Diderot). Mestre em Psicanálise (Universidade Paris 8). Mestre em Psicologia (UFMG). Professora adjunta do curso de Psicologia do UNI-BH.

fabianabap@ig.com.br

Renata Mattos-Avril

Universidade Sophia Antipolis, Faculdade de Letras, Artes e Ciências Humanas, Departamento de Psicologia. Nice, França.

renatamattos.rm@gmail.com 